\title{
Kabuki syndrome
}

INSERM

\section{Source}

INSERM. (1999). Orphanet: an online rare disease and orphan drug data base. Kabuki syndrome. ORPHA:2322

Kabuki syndrome (KS) is a multiple congenital anomaly syndrome characterized by typical facial features, skeletal anomalies, mild to moderate intellectual disability and postnatal growth deficiency. 